\title{
Diferentes vias de administração de probiótico sobre o desempenho, o rendimento de carcaça e a população microbiana do intestino delgado de codornas de corte
}

\author{
Luciana Kazue Otutumi ${ }^{1^{*}}$, Antonio Claudio Furlan ${ }^{2}$, Elias Nunes Martins ${ }^{2}$, Celso Vataru \\ Nakamura $^{3}$, Elis Regina de Moraes Garcia ${ }^{4}$, Priscila Ventura Loose ${ }^{2}$ \\ 1 Programa de Pós-Graduação em Zootecnia - Universidade Estadual de Maringá - UEM, Av. Colombo, 5790, CEP: 87020-900, \\ Maringá, $P R$. \\ 2 Departamento de Zootecnia - UEM, Maringá, PR. \\ ${ }^{3}$ Departamento de Microbiologia - UEM, Maringá, $P R$. \\ ${ }^{4}$ Departamento de Zootecnia da Universidade Estadual do Mato Grosso do Sul, Unidade Universitária de Aquidauana. Rodovia \\ Aquidauana Cera, km 12, CEP: 79200-000, Aquidauana, MS.
}

RESUMO - Objetivou-se avaliar duas vias de administração de probiótico sobre o desempenho, o rendimento de carcaça e a população microbiana do intestino delgado de codornas de corte. Foram utilizadas 1.050 codornas machos e fêmeas de 1 dia de idade distribuídas em delineamento inteiramente casualizado com três tratamentos (controle, probiótico na água bebida e probiótico na ração) e cinco repetições de 70 aves. A cada sete dias, foram avaliados o ganho de peso, o consumo de ração, a conversão alimentar e a viabilidade criatória. Aos 7 e aos 14 dias, 15 aves foram abatidas para determinação da contagem de Lactobacillus sp., enterobactérias e Escherichia coli do intestino delgado e, aos 35 dias, 30 aves foram abatidas para avaliação do rendimento de carcaça e de cortes. Dos 7 aos 14 dias, as codornas que receberam probiótico na ração, em relação àquelas que receberam na água de bebida, apresentaram menor consumo de ração, porém essa diferença no consumo não afetou o ganho de peso, o que levou à melhora na conversão alimentar. O rendimento de carcaça, a contagem de Lactobacillus sp., de enterobactérias e de Escherichia coli não foram influenciados pela adição do probiótico. O fornecimento de probiótico não melhora o desempenho e o rendimento de carcaça e não altera a microbiota do intestino delgado de codornas de corte.

Palavras-chave: conversão alimentar, Escherichia coli, lactobacilos

\section{Different ways of administering probiotic on performance, yield carcass and small intestine microbial population of meat quail}

\begin{abstract}
The objective of this study was to evaluate the effect of different ways of administering probiotic on performance, carcass yield and small intestine microbial population of meat quail. One thousand and fifty quails, one-day old males and females were used, distributed in a randomized completedesign with three treatments (control, probiotic in drinking water and probiotic in feed) and five replications of seventy quail each. Every seven days, the quails were weighed to evaluate weight gain (WG), feed intake (FI), feed conversion (FC) and growth viability. At 7 and 14 days, fifteen quails were slaughtered to perform the count of Lactobacillus sp., enterobacteria and Escherichia coli of the small intestine at 35 days, 30 quails were slaughtered to evaluate the carcass and cut yields. From 7 to 14 days of age, the quails fed probiotic in the ration, compared to those fed probiotic in the drinking water, showed lower feed intake, which did not affect weight gain and improved feed conversion. Carcass yield, count of Lactobacillus sp., enterobacteria and Escherichia coli were not influenced by probiotic addition. The probiotic do not improve performance, carcass yield and also do not alter small intestine microbiota of meat quail.
\end{abstract}

Key Words: Escherichia coli, feed conversion, lactobacillus

\section{Introdução}

A industrialização e a necessidade de atender ao mercado globalizado exigem dos produtores rurais a utilização de modernas tecnologias na produção animal. Nesse contexto, um empreendimento agropecuário lucrativo é quase impossível sem o uso de tecnologias que busquem a eficiência produtiva, o que leva à

Recebido em 18/7/2008 e aprovado em 14/1/2009.

Correspondências devem ser enviadas para: otutumi@unipar.br

*Endereço atual: Universidade Paranaense - UNIPAR - Campus II, Rodovia PR-480, Km 2, Caixa Postal 106, CEP: 87502-970, Umuarama - PR. 
dependência cada vez maior do uso nos animais de criação de substâncias químicas como os aditivos, em especial os antimicrobianos (Palermo-Neto, 2001).

Além disso, nos últimos anos, com a intensificação dos sistemas de produção animal, os animais são criados em densidades cada vez mais elevadas, o que tem aumentado os riscos de disseminação de microrganismos patogênicos, visto que os sistemas de desinfecção das granjas não permitem a criação de animais em ambientes isentos desses microrganismos (Santos et al., 2003). Dessa forma, o uso de aditivos, como os antimicrobianos promotores de crescimento, tornou-se quase uma obrigatoriedade.

Entretanto, as atuais restrições impostas pela União Europeia, a exigência dos consumidores por produtos livres de resíduos e a preocupação relacionada à possibilidade do desenvolvimento de resistência bacteriana cruzada entre humanos e animais têm levado produtores e pesquisadores à busca por alternativas aos usuais promotores de crescimento, entre eles, os probióticos.

Uma das bases teóricas que apoiam o uso dos probióticos na alimentação animal é a de que a substituição da microbiota intestinal normal, em particular Escherichia coli, por outra, como os Lactobacillus sp., melhoraria o desempenho e aumentaria a resistência à colonização por microrganismos patogênicos, por melhorar a saúde e a digestão dos alimentos (Dale, 1992).

Em codornas de postura, Oliveira et al. (2004) avaliaram o efeito da adição de probiótico na água de bebida e ração e diferentes antibióticos via água de bebida ou ração ou ambos durante a primeira semana de vida e não encontraram diferenças significativas no desempenho no período de 1 a 21 dias. Pesquisas desenvolvidas por Corrêa et al. (2000 e 2003) e Pelicano et al. (2003), no entanto, têm indicado melhorias no rendimento de pernas com a adição do probiótico.

O objetivo neste trabalho foi avaliar o efeito de diferentes vias de administração de probiótico sobre o desempenho, o rendimento de carcaça e a população microbiana do intestino delgado de codornas de corte.

\section{Material e Métodos}

O experimento foi conduzido no Setor de Avicultura da Fazenda Experimental de Iguatemi (FEI) da Universidade Estadual de Maringá (UEM) no período de março a abril de 2005. Utilizaram-se 1.050 codornas de corte (Coturnix coturnix sp.), machos e fêmeas de 1 dia de idade, por um período experimental de 35 dias, alojadas em 15 boxes com 70 aves, com cinco boxes para cada tratamento.
Avaliaram-se um tratamento controle, sem adição de probiótico, e duas diferentes vias de administração do probiótico: água de bebida e ração. O probiótico continha em média $1,6 \times 10^{9}$ unidades formadoras de colônia por grama (ufc/g) de um pool de Lactobacillus sp. e foi fornecido somente na primeira semana do período experimental (1 a 7 dias de idade) na dosagem de $100 \mathrm{~g} /$ tonelada, segundo recomendações do fabricante FATEC ${ }^{\circledR}$.

A quantidade de probiótico a ser suplementada na ração dos animais foi calculada com base na quantidade de ração a ser consumida pelos animais durante a primeira semana de vida. Com base nesse cálculo e tendo em vista a pequena quantidade de ração, a ração foi misturada em um misturador Y por um período de 15 minutos. Para os animais que receberam probiótico na água de bebida, o probiótico foi adicionado diariamente à água não-clorada.

Odelineamento experimental utilizado foi inteiramente casualizado com três tratamentos e cinco repetições. O suplemento mineral vitamínico (utilizado nas rações) foi formulado para não conter qualquer tipo de aditivo.

A ração, fornecida à vontade durante todo o período experimental, foi formulada segundo exigências de Barral (1994), considerando a composição dos alimentos descrita por Rostagno et al. (2005) (Tabela 1).

O desempenho das aves foi avaliado por meio do consumo ração, do ganho de peso, da conversão alimentar e da viabilidade criatória (aves vivas/total de aves*100) no período experimental.

Aos 35 dias de idade, foram retiradas ao acaso quatro aves de cada unidade experimental ( 20 aves por tratamento)

Tabela 1 - Composição da ração experimental

\begin{tabular}{|c|c|}
\hline Ingrediente & $\% \mathrm{MS}$ \\
\hline Milho & 41,10 \\
\hline Farelo de soja, $45 \%$ & 50,45 \\
\hline Calcário & 1,05 \\
\hline Fosfato bicálcico & 1,22 \\
\hline Sal comum & 0,36 \\
\hline Suplemento vitamínico e mineral ${ }^{1}$ & 0,40 \\
\hline Óleo de soja & 5,41 \\
\hline BHT & 0,01 \\
\hline \multicolumn{2}{|l|}{ Valores calculados } \\
\hline Energia metabolizável (kcal/kg) & 3.000 \\
\hline Proteína bruta $(\%)$ & 26,00 \\
\hline Fibra bruta $(\%)$ & 4,09 \\
\hline Cálcio $(\%)$ & 0,80 \\
\hline Fósforo disponível (\%) & 0,30 \\
\hline Lisina total $(\%)$ & 1,55 \\
\hline Metionina + cistina total $(\%)$ & 0,83 \\
\hline \multicolumn{2}{|c|}{$\begin{array}{l}{ }^{1} \text { Composição por kg do produto: vit. A, } 2500.000 \mathrm{UI} \text {; vit. } \mathrm{D}_{3}, 625.000 \mathrm{UI} \text {; vit } \\
\mathrm{E}, 3.750 \mathrm{mg} \text {; vit } \mathrm{B}_{1}, 138 \mathrm{mg} \text {; vit. } \mathrm{B}_{2}, 1.250 \mathrm{mg} \text {; vit. } \mathrm{B}_{6}, 523 \mathrm{mg} \text {; vit } \mathrm{B}_{12}, 5.000 \mu \\
\text { vit. } \mathrm{K}_{3}, 750 \mathrm{mg} \text {; ácido fólico, } 112 \mathrm{mg} \text {; pantotenato de cálcio, } 2.000 \mathrm{mg} \text {; niacina } \\
7.500 \mathrm{mg} \text {; metionina, } 275.000 \mathrm{mg} \text {; colina, } 87.500 \mathrm{mg} \text {; selênio, } 63 \mathrm{mg} \\
\text { antioxidante, } 2.500 \mathrm{mg} \text {; iodo, } 240 \mathrm{mg} \text {; veículo q.s.p., } 1.000 \mathrm{~g} \text {; zinco, } 15.750 \mathrm{mg} \\
\text { ferro, } 12.250 \mathrm{mg} \text { : manganês. } 19.375 \mathrm{mg} \text {; cobre, } 3.900 \mathrm{mg} \text {; cobalto } 50 \mathrm{mg} \text {. }\end{array}$} \\
\hline
\end{tabular}

R. Bras. Zootec., v.39, n.1, p.158-164, 2010 
para avaliação dos rendimentos de carcaça e dos cortes. As aves foram identificadas por meio de anilhas numeradas colocadas nas patas e submetidas a jejum alimentar de 8 horas, com água à vontade. Após a pesagem individual, $\mathrm{o}$ abate foi realizado por degola completa entre os ossos occipital e atlas. As aves foram escaldadas por 15 a 20 segundos a uma temperatura de 55 a $60^{\circ} \mathrm{C}$ e, a seguir, submetidas a depena manual. Sequencialmente, efetuaram-se a evisceração manual e a pesagem da carcaça. Os cortes da carcaça foram separados e pesados para determinação dos rendimentos de peito, pernas, dorso e asa.

No cálculo de rendimento de carcaça, foi considerado o peso da carcaça eviscerada, sem os pés, a cabeça e a gordura abdominal, em relação ao peso vivo. Para o rendimento de cortes, foi considerado o peso do peito inteiro com pele, das pernas (coxa e sobrecoxa com pele), do dorso e das asas, calculado em relação ao peso da carcaça eviscerada.

Aos 7 e 14 dias de idade, foram escolhidas aleatoriamente uma ave de cada unidade experimental (cinco aves por tratamento) para coleta do intestino delgado (com conteúdo) com o objetivo de avaliar a influência da administração do probiótico sobre a contagem total de Lactobacillus sp., enterobactérias e Escherichia coli.

Para isso, as aves foram abatidas por meio de degola completa entre os ossos occipital e atlas. O material utilizado para coleta do intestino delgado foi previamente esterilizado em autoclave por 30 minutos e o intestino delgado, depois de separado, foi pesado em placas de petri estéreis e, em seguida, fragmentado para acondicionamento em tubos com tampa de rosca, contendo $9 \mathrm{~mL}$ de solução salina estéril e pérolas de vidro para auxiliar na trituração e homogeneização do material colhido para posterior análise microbiológica. Esses tubos foram mantidos em banho de gelo até as análises, realizadas no Laboratório de Microbiologia da UEM. Da coleta do material até o processamento, as amostras permaneceram em banho de gelo por um período de 3 a 6 horas.

A contagem total de Lactobacillus sp. foi realizada utilizando-se o ágar Rogosa (Lactobacillus Selective Agar) e a contagem total de enterobactérias, o ágar EMB (Eosin Methylene-blue Lactose Sucrose Agar), de acordo com metodologia descrita por Merck (2000).

As amostras foram diluídas até $10^{-4}$, plaqueadas em duplicata e incubadas a $37{ }^{\circ} \mathrm{C}$ por 72 e 24 horas para os meios Rogosa e EMB, respectivamente. Para o ágar Rogosa, foi necessário usar a técnica de profundidade. As placas, depois de semeadas e cobertas com o restante do agar, foram colocadas em jarras de anaerobiose. Após a incubação, as colônias foram contadas e os resultados foram expressos em ufc/g (unidade formadora de colônia/ grama) de intestino delgado.

As colônias isoladas que cresceram no ágar EMB foram estocadas em ágar nutriente e submetidas, posteriormente, aos testes bioquímicos utilizando-se os meios para identificação bacteriana da Probac ${ }^{\circledR}$ do Brasil (Enterokit B) com o objetivo de realizar a identificação bacteriana.

Para análise estatística da contagem de Escherichia coli no material colhido, utilizaram-se somente duas repetições de cada tratamento, enquanto nas demais análises utilizaram-se cinco repetições. A análise estatística das carcterísticas de desempenho e do rendimento de carcaça foi realizada considerando o modelo estatístico: $\mathrm{Y}_{\mathrm{ij}}=\mu+\mathrm{T}_{\mathrm{i}}+\mathrm{e}_{\mathrm{ij}}$; em que $\mathrm{Y}_{\mathrm{ij}}=$ valores das variáveis avaliadas na unidade experimental que receberam o tratamento $i ; \mu=$ constante geral; $\mathrm{T}_{\mathrm{i}}=$ efeito do tratamento $\mathrm{i}, \mathrm{i}=1,2,3 ; \mathrm{e}_{\mathrm{ij}}=$ erro aleatório associado a cada observação $\mathrm{Y}_{\mathrm{ij}}, \mathrm{e}_{\mathrm{ij}} \sim \mathrm{N}\left(0, \sigma^{2}\right)$.

Os dados de desempenho e do rendimento de carcaça foram submetidos à análise de variância e as médias comparadas pelo teste Tukey a 5\% de significância, utilizando-se o programa SAEG (UFV, 1999).

A análise estatística da microbiologia foi feita por meio do método de modelos lineares generalizados (Nelder \& Wedderburn, 1972), admitindo-se distribuição gama com função de ligação recíproca e, nesse caso, o modelo: $\eta=\mu+T_{i}+I_{j}+e_{i j k}$; em que: $\eta=$ valores das variáveis avaliadas na unidade experimental que receberam o tratamento $\mathrm{i}$, na idade $\mathrm{j} ; \mu=$ constante geral; $\mathrm{T}_{\mathrm{i}}=$ efeito do tratamento $\mathrm{i}, \mathrm{i}=1,2,3 ; \mathrm{I}_{\mathrm{j}}=$ efeito da idade $\mathrm{j}, \mathrm{j}=1,2$.

Assim, conforme McCulloch \& Searle (2001), quando a distribuição foi gama, a esperança de $\mathrm{Y}$ (média da variável dependente) foi determinada por $\mathrm{E}\left(\mathrm{Y}_{\mathrm{ijk}}\right)=1 / \eta_{\mathrm{ijk}}$ e, no caso da distribuição normal, foi determinada por $\mathrm{E}$ $\left(Y_{i j k}\right)=\eta_{i j k}$.

\section{Resultados e Discussão}

No decorrer do período experimental, a temperatura média registrada no interior do galpão foi máxima $30^{\circ} \mathrm{C} \mathrm{e}$ mínima de $24{ }^{\circ} \mathrm{C}$. No período de 1 a 7 dias de idade, período no qual os animais receberam o probiótico, respectivamente, via água de bebida e ração, não houve diferenças $(\mathrm{P}>0,05)$ no consumo ração, no ganho de peso e na conversão alimentar (Tabela 2).

Nos períodos de 1 a 14 e de 1 a 21 dias de idade, os animais que receberam probiótico via ração apresentaram consumo de ração significativamente menor em comparação aos demais, porém o ganho de peso não foi influenciado, 
Tabela 2 - Desempenho e viabilidade de criação de codornas de corte recebendo probiótico (Lactobacillus sp.) administrado por duas vias

\begin{tabular}{|c|c|c|c|c|c|}
\hline \multirow[t]{2}{*}{ Variável } & \multirow[t]{2}{*}{ Idade } & \multirow[t]{2}{*}{ Controle } & \multicolumn{2}{|c|}{ Via de administração do probiótico } & \multirow[t]{2}{*}{$\mathrm{CV} \%{ }^{1}$} \\
\hline & & & Água & Ração & \\
\hline \multirow[t]{5}{*}{ Consumo de ração $(\mathrm{g})$} & $1-7$ & 39,04 & 38,59 & 38,36 & 3,15 \\
\hline & $1-14$ & $134,10 \mathrm{a}$ & $135,60 \mathrm{a}$ & $129,08 \mathrm{~b}$ & 1,95 \\
\hline & $1-21$ & $262,10 \mathrm{a}$ & $264,43 \mathrm{a}$ & $255,87 \mathrm{~b}$ & 1,42 \\
\hline & $1-28$ & $442,65 \mathrm{a}$ & $435,38 \mathrm{ab}$ & $426,99 b$ & 1,22 \\
\hline & $1-35$ & $660,65 \mathrm{a}$ & $642,74 b$ & $641,88 \mathrm{~b}$ & 1,18 \\
\hline \multirow[t]{5}{*}{ Ganho de peso $(\mathrm{g})$} & $1-7$ & 24,83 & 23,60 & 24,17 & 4,40 \\
\hline & $1-14$ & $77,68 \mathrm{a}$ & $75,27 b$ & $76,30 \mathrm{ab}$ & 1,47 \\
\hline & $1-21$ & 149,00 & 147,06 & 147,58 & 1,13 \\
\hline & $1-28$ & 208,87 & 206,06 & 206,12 & 1,42 \\
\hline & $1-35$ & 257,37 & 252,39 & 254,15 & 1,42 \\
\hline \multirow[t]{5}{*}{ Conversão alimentar (g/g) } & $1-7$ & 1,57 & 1,64 & 1,59 & 3,60 \\
\hline & $1-14$ & $1,73 b$ & $1,80 \mathrm{a}$ & $1,69 b$ & 1,96 \\
\hline & $1-21$ & $1,76 \mathrm{ab}$ & $1,80 \mathrm{a}$ & $1,73 b$ & 1,32 \\
\hline & $1-28$ & $2,12 \mathrm{a}$ & $2,11 \mathrm{a}$ & $2,07 b$ & 1,14 \\
\hline & $1-35$ & 2,57 & 2,55 & 2,53 & 0,99 \\
\hline Viabilidade de criação (\%) & $1-35$ & 98,286 & 98,286 & 97,714 & 1,823 \\
\hline
\end{tabular}

${ }^{1}$ Coeficiente de variação.

a,b Na mesma linha, médias seguidas de letras diferentes, diferem $(\mathrm{P}<0,05)$ pelo teste Tukey.

o que levou a melhora na conversão alimentar em comparação à dos animais que receberam o probiótico via água de bebida, evidenciando o efeito positivo da adição do probiótico na ração, via recomendada pelo fabricante.

Esses resultados diferem dos obtidos por Maiorka et al. (2001) e Pelicano et al. (2004), que encontraram melhores valores de conversão alimentar no período de 1 a 21 dias, mas não notaram redução no consumo de ração em frangos de corte alimentados com dieta suplementada com probiótico.

Por outro lado, Corrêa et al. (2003) encontraram tanto redução no consumo de ração quanto melhora na conversão alimentar de frangos de corte no período de 1 a 20 dias, quando adicionaram probiótico à base de Lactobacillus acidophilus e casei; Streptococcus salivarium e faecium; Bacillus subtilis e toyoi e Saccharomyces cerevisiae à ração das aves. Essas variações na resposta aos probióticos podem estar relacionadas à instabilidade da microbiota das aves na fase inicial, a qual está sujeita a alterações durante a primeira semana de vida das aves (Bunyan et al., 1977).

Do $1^{\mathrm{o}}$ ao $28^{\circ}$ dia de idade, os animais que receberam probiótico via ração continuaram apresentando menor consumo de ração com mesmo ganho de peso, portanto com melhor conversão alimentar (Tabela 2). No período total (1 a 35 dias de idade), os animais do grupo controle consumiram significativamente mais ração que aqueles que receberam probiótico na água de bebida ou na ração.

Entre os benefícios do uso dos probióticos na alimentação animal, destacam-se o aumento da disponibilidade de aminoácidos nos locais de absorção (Kozasa, 1989), economia de energia e aumento da disponibilidade de vitaminas e enzimas (Fuller, 1989), o que poderia explicar o fato de os animais que receberam probiótico via água de bebida ou ração terem menor consumo de ração no período de 1 a 35 dias, sem que isso afetasse o ganho de peso e a conversão alimentar.

Os resultados de ganho de peso e conversão alimentar de frangos de corte obtidos neste trabalho corroboram os encontrados por Henrique et al. (1998 a,b), Loddi et al. (2002), Pedroso et al. (2002), Corrêa et al. (2003), Lima et al. (2003) e Pelicano et al. (2004), que não constataram efeito da adição do probiótico sobre esses parâmetros no período de 1 a 42 dias.

A ausência de resultados benéficos com o uso dos probióticos pode ser explicada pela diferença na quantidade e nas características das cepas do microrganismo utilizado, e pelo não-atendimento dos requisitos para atuar como probiótico (Loddi et al., 2000).

A viabilidade no período de 1 a 35 dias (Tabela 2) não foi influenciada $(\mathrm{P}>0,05)$ pela adição do probiótico e está de acordo com os resultados verificados em frangos de corte por Pedroso et al. (2002) nos períodos de 1 a 21 e 1 a 42 dias e Pelicano et al. (2004) no período de 1 a 42 dias.

Os resultados de viabilidade obtidos neste experimento provavelmente estão correlacionados à boa condição sanitária em que as aves foram criadas, já que os animais do grupo controle, mesmo não recebendo qualquer tipo de aditivo, apresentaram alta viabilidade.

Nessas condições de mínimo estresse e desafio, os probióticos podem não manifestar resultados evidentes da eficácia de sua utilização (Fox, 1988; Dale, 1992; Maruta, 1993). Os resultados de rendimento de carcaça e de cortes não foram influenciados $(\mathrm{P}>0,05)$ pelo fornecimento do probiótico (Tabela 3). 
Tabela 3 - Rendimento de carcaça e de cortes de codornas de corte, recebendo o probiótico Lactobacillus sp. por duas vias de administração

\begin{tabular}{lccc}
\hline Rendimento\% & Controle & \multicolumn{2}{c}{ Via de administração do probiótico } \\
\cline { 3 - 4 } & & Água & Ração \\
\hline Carcaça & 70,04 & 70,01 & 70,27 \\
Asas & 6,24 & 6,37 & 6,35 \\
Dorso & 24,78 & 25,10 & 24,45 \\
Pernas & 23,28 & 24,04 & 23,88 \\
Peito & 45,18 & 43,96 & 4,84 \\
\hline
\end{tabular}

${ }^{1}$ Coeficiente de variação.

Resultados não diferiram $(\mathrm{P}>0,05)$ pelo teste $\mathrm{F}$.

Esses resultados corroboram os obtidos por Henrique et al. (1998 a,b), Loddi et al (2000 e 2002), Maiorka et al. (2001) e Vargas Jr. et al. (2002), que não observaram melhora nas características de carcaça de frangos de corte com o uso do probiótico. Por outro lado, Corrêa et al. (2003) notaram que frangos de corte machos alimentados com poliprobiótico constituído de cepas de Lactobacillus acidophilus e casei, Streptococcus salivarium e faecium, Bacillus subtilis e toyoi e Saccharomyces cerevisae apresentaram maior rendimento de coxa em relação àqueles que receberam bacitracina de zinco e probiótico (B. subtilis).

Resultados semelhantes, com melhorias no rendimento de pernas, foram obtidos por Pelicano et al. (2003) em frangos de corte que receberam diferentes probióticos no período de 1 a 45 dias de idade.

Apesar de a metodologia de análise estatística utilizada ser adequada a este tipo de dados, não foram encontradas diferenças na população microbiana (Tabelas 4, 5, e 6), provavelmente em razão da alta variabilidade dos dados. A idade e o fornecimento de probiótico não alteraram a contagem total de Lactobacillus sp. no intestino delgado das codornas (Tabela 4).

Esses resultados são similares aos obtidos por Netherwood et al. (1999), que também não verificaram alteração na contagem de Lactobacillus sp. ao adicionarem probiótico à base de Enterococcus faecium na água de bebida de galinhas. Jin et al. (1998) notaram que, aos 10 dias de idade, a população de Lactobacillus no intestino delgado de frangos que receberam $0,15 \%$ de uma cultura de Lactobacillus foi significativamente maior que nas aves do grupo controle. No entanto, a quantidade de Lactobacillus fornecida aos animais foi 15 vezes superior à utilizada neste experimento.

Em trabalho mais recente, Strompfova et al. (2005) verificaram que a administração oral de Lactobacillus fermentum por meio de inoculação oral e na água de bebida aumentou a contagem de Lactobacillus e reduziu a contagem de Escherichia coli nas fezes de codornas japonesas após um período de sete dias.

Provavelmente, os resultados obtidos neste experimento refletem à não-colonização do intestino delgado pelo Lactobacillus utilizado, uma vez que o efeito do uso dos Lactobacillus como promotor de crescimento se deve ao fato de a bactéria ser capaz de sobreviver e colonizar o trato gastrintestinal até que suas funções benéficas possam ser exercidas (Jin et al., 1998), fato que não ocorreu.

Tabela 4 - Contagem total de Lactobacillus sp. (ufc/g) no intestino delgado de codornas de corte aos 7 e aos 14 dias de idade recebendo o probiótico Lactobacillus sp. por duas vias de administração

\begin{tabular}{lccr}
\hline Item & Controle & \multicolumn{2}{c}{$\begin{array}{c}\text { Vias de administração } \\
\text { do probiótico }\end{array}$} \\
\cline { 3 - 4 } & & \multicolumn{2}{c}{ água } \\
\hline & & 7 dias & Ração \\
Média & $15,93 \times 10^{4}$ & $229,85 \times 10^{4}$ & $45,24 \times 10^{4}$ \\
Desvio-padrão & 25,33 & 396,80 & 58,22 \\
& & 14 dias & \\
Média & $333,19 \times 10^{4}$ & $75,26 \times 10^{4}$ & $362,53 \times 10^{4}$ \\
Desvio-padrão & 570,23 & 116,95 & 370,77 \\
\hline S resur
\end{tabular}

Os resultados não diferiram $(\mathrm{P}>0,05)$ pelo teste Student.

Tabela 5 - Contagem total de enterobactérias (ufc/g) no intestino delgado de codornas de corte aos 7 e aos 14 dias de idade recebendo o probiótico Lactobacillus sp. por duas vias de administração

\begin{tabular}{lccr}
\hline Item & Controle & \multicolumn{2}{c}{$\begin{array}{c}\text { Vias de administração } \\
\text { do probiótico }\end{array}$} \\
\cline { 3 - 4 } & & água & Ração \\
\hline \multirow{3}{*}{ Média } & $262,8 \times 10^{4}$ & $449,5 \times 10^{4}$ & $170,3 \times 10^{4}$ \\
Desvio-padrão & 358,53 & 545,27 & 151,19 \\
& & 14 dias & \\
Média & $843,6 \times 10^{4}$ & $107,5 \times 10^{4}$ & $1244,3 \times 10^{4}$ \\
Desvio-padrão & 1621,51 & 41,92 & 1971,98 \\
\hline Os resultados não diferiram $(\mathrm{P}>0,05)$ pelo teste Student.
\end{tabular}

R. Bras. Zootec., v.39, n.1, p.158-164, 2010 
Tabela 6 - Contagem total de Escherichia coli (ufc/g) no intestino delgado de codornas de corte recebendo o probiótico por duas vias de administração

\begin{tabular}{lccc}
\hline Item & Controle & \multicolumn{2}{c}{$\begin{array}{c}\text { Vias de administração } \\
\text { do probiótico }\end{array}$} \\
\cline { 3 - 4 } & & água & Ração \\
\hline Média & $21,10 \times 10^{4}$ & $19,22 \times 10^{4}$ & $51,41 \times 10^{4}$ \\
Desvio-padrão & 34,70 & 22,20 & 66,59 \\
& Idade & 7 & 14 \\
Média & & $49,21 \times 10^{4}$ & $11,94 \times 10^{4}$ \\
Desvio-padrão & & 54,42 & 20,15 \\
\hline
\end{tabular}

Os resultados não diferiram $(\mathrm{P}>0,05)$ pelo teste Student.

Rostagno et al. (2004) relataram que uma das explicações para a ausência de efeitos benéficos dos probióticos em experimentos com frangos de corte pode ser a falta de desafio, em decorrência do pouco uso e da boa higiene das instalações onde foram realizados os experimentos, que evidentemente não são parecidas com as condições sanitárias normalmente encontradas nos aviários comerciais.

A idade e o fornecimento de probiótico não reduziram $(\mathrm{P}>0,05)$ a contagem total de enterobactérias (Tabela 5).

Jin et al. (1998) não observaram redução na população de coliformes do intestino delgado de frangos de corte aos $10,20,30$ e 40 dias de idade recebendo cultura de Lactobacillus em concentrações de 0,$05 ; 0,10$ e $0,15 \%$. Entretanto, no ceco, verificaram redução significativa com as três concentrações aos 10 dias; 0,05 e $0,10 \%$ aos 20 dias e de $0,05 \%$ aos 30 dias. Os resultados obtidos por esses autores evidenciam diferença no comportamento da microbiota intestinal de acordo com as concentração do probiótico utilizado, com a porção do intestino e a idade em que foi realizada a mensuração. Uma das bases teóricas para o uso dos probióticos na alimentação animal é que a substituição da flora intestinal normal (sobretudo Escherichia coli) por outra flora, como os Lactobacillus sp., melhoraria o desempenho e aumentaria a resistência à colonização por microrganismos patogênicos, por melhorar a saúde e a digestão dos alimentos (Dale, 1992).

Neste experimento, porém, não foi verificada redução na contagem total de Escherichia coli com a suplementação do probiótico (Tabela 6), consequentemente, não foi constatada melhora no desempenho, o que pode refletir a ausência da adesão do probiótico ao epitélio intestinal e posterior colonização pela inabilidade de utilizar os substratos disponíveis (Fuller, 1986).

Diferentemente dos resultados obtidos neste experimento, Jin et al. (1996) e Edens et al. (1997) verificaram efeito protetor contra a colonização por Escherichia coli em frangos de corte que receberam, respectivamente, probiótico à base de Bacillus subtilis ou Lactobacillus sp. e Lactobacillus reuteri.

Os valores de contagem de Lactobacillus sp. encontrados no intestino delgado das codornas foi inferior ao mínimo de $10^{7} \mathrm{ufc} / \mathrm{g}$ (Tabela 5) necessário para o controle da população de Escherichia coli, que, de acordo com Fuller (1977), depende da presença de número suficiente de Lactobacillus.

\section{Conclusões}

A adição do probiótico (Lactobacillus sp.) via água ou ração não melhora o desempenho, o rendimento de carcaça e a população microbiana do intestino delgado de codornas de corte.

\section{Referências}

BARRAL, A.D. Manual de la Codorniz: cria industrial y para la caza. Lleida: Dilagro, 1994. 268p.

BUNYAN, J.; JEFRIES, L.; SAYERS, J.R. et al. Antimicrobial substances and chick growth promotion: the growth-promoting activities of antimicrobial substances, including fifty-two used either in therapy or as dietary additives. British Poultry Science, v.18, p.283-294, 1977.

CORRÊA, G.S.S.; GOMES, A.V.C.; CORRÊA, A.B. et al Desempenho de frangos de corte alimentados com diferentes promotores de crescimento. In: REUNIÃO ANUAL DA SOCIEDADE BRASILEIRA DE ZOOTECNIA, 37., 2000 , Viçosa, MG. Anais...Viçosa, MG: Sociedade Brasileira de Zootecnia, 2000. p.37.

CORRÊA, G.S.S.; GOMES, A.V.C.; CORRÊA, A.B. et al. Efeito de antibiótico e probióticos sobre o desempenho e rendimento de carcaça de frangos de corte. Arquivo Brasileiro de Medicina Veterinária e Zootecnia, v.55, n.4, p.467-473, 2003.

DALE, N. Probióticos para aves. Avicultura professional, v.10, p.88-89, 1992.

EDENS, F.W.; PARKHURST, C.R.; CASAS, I.A. et al. Principles of ex ovo competitive exclusion and in ovo administration of Lactobacillus reuteri. Poultry Science, v.76, p.179-196, 1997.

FOX, S.M. Probiotics: intestinal inoculants for production animals. Veterinary Medicine, v.83, p.806-830, 1988.

FULLER, R. Probiotics: the scientific basis. London: Chapman \& Hall, 1989. 307p.

FULLER, R. Probiotics. Journal of Applied Bacteriology, v.15, p.1-7, 1986 (suppl.).

FULLER, R. The importance of lactobacili in maintaining normal microbial balance in the crop. British Poultry Science, v.18, p.85-94, 1977.

HENRIQUE, A.P.F.; FARIA, D.E.; FRANZOLIN, R. et al. Uso de probióticos e antibióticos como promotores de crescimento para frangos de corte. In: REUNIÃO ANUAL DA SOCIEDADE BRASILEIRA DE ZOOTECNIA, 35., 1998, Botucatu. Anais.. Botucatu: Sociedade Brasileira de Zootecnia, [1998a]. (CD-ROM).

HENRIQUE, A.P.F.; FARIA, D.E.; FRANZOLIN, R. et al. Efeito de ácido orgânico, probiótico e antibiótico sobre o desempenho e rendimento de carcaça de frangos de corte. In: REUNIÃO ANUAL DA SOCIEDADE BRASILEIRA DE ZOOTECNIA, 35. 1998, Botucatu. Anais... Botucatu: Sociedade Brasileira de Zootecnia, [1998b]. (CD-ROM).

JIN, L.Z.; HO, Y.W.; ABDULLAH, N. et al. Influence of dried Bacillus subtilis and Lactobacilli cultures on intestinal 
microflora and performance in broilers. Asian-Australian Journal Animal Science, v.9, p.397-404, 1996.

JIN, L.Z.; HO, Y.W.; ABDULLAH, N. et al. Growth performance, intestinal microbial populations, and serum cholesterol of broilers fed diets containing Lactobacillus cultures. Poultry Science, v.77, p.1259-1265, 1998.

KOZASA, M. Probiotics for animal use in Japan. Veterinary Science Technology Off. Int. Epiz., v.8, n.2, p.517-531, 1989.

LIMA, A.C.F.; PIZAURO JR., J.M.; MACARI, M. et al. Efeito do uso de probiótico sobre o desempenho e atividade de enzimas digestivas de frangos de corte. Revista Brasileira de Zootecnia, v.32, n.1, p.200-207, 2003.

LODDI, M.M.; GONZALES, E.; TAKITA, T.S. et al. Uso de probiótico e antibiótico sobre o desempenho, o rendimento e a qualidade de carcaça de frangos de corte. Revista Brasileira de Zootecnia, v.29, n.4, p.1124-1131, 2000

LODDI, M.M.; TUCCI, F.M.; HANNAS, M.I. et al. Probióticos, mananoligossacarídeos + ácidos orgânicos em dietas de frangos. In: REUNIÃO ANUAL DA SOCIEDADE BRASILEIRA DE ZOOTECNIA, 39., 2002, Recife. Anais... Recife: Sociedade Brasileira de Zootecnia, [2002]. (CD-ROM).

MAIORKA, A.; SANTIN, E.; SUGETA, S.M. et al. Utilização de prebióticos, probióticos ou simbióticos em dietas para frangos. Revista Brasileira de Ciência Avícola, v.3, n.1, p.75-82, 2001.

MARUTA, K. Probióticos e seus benefícios. In: CONFERÊNCIA APINCO DE CIÊNCIA E TECNOLOGIA AVÍCOLAS, 1993, Santos. Anais... Santos: Fundação Apinco de Ciência e Tecnologia Avícolas, 1993. p.203-219.

MCCULLOCH, C.E.; SEARLE, S.R. Generalized, linear, and mixed models. New York: John Willey, 2001. 325p.

MERCK. Microbiology manual. Darmstadt: Merck KGoA, 2000. $407 \mathrm{p}$.

NELDER, J.A.; WEDDERBURN, W.M. Generalized linear models. Journal Royal Statistical Society, v.135, n.3, p.370-384, 1972.

NeTherwood, T.; GILBERT, H.J.; PARKER, D.S. et al. Probiotics shown to change bacterial community structure in the avian gastrointestinal tract. Applied and Environmental Microbiology, v.65, n.11, p.5134-5138, 1999.

OLIVEIRA, B.L.; OLIVEIRA, D.D.; OLIVEIRA, A.I.G. Utilização de probióticos e antibióticos na fase inicial da criação de codornas (Coturnix coturnix japonica). In: SIMPÓSIO DE COTURnicultura, 2., 2004, Lavras. Anais... Lavras: Universidade Federal de Lavras, [2004]. (CD-ROM).
PALERMO-NETO, J. Resíduos de antimicrobianos em alimentos. Revista CFMV, 2001, p.65-71.

PEDROSO, A.A.; MENTEN, J.F.M.; LONGO, F.A. et al. Desempenho de frangos de corte recebendo ração suplementada com aditivos microbianos e criados em baterias ou em galpão convencional In: REUNIÃO ANUAL DA SOCIEDADE BRASILEIRA DE ZOOTECNIA, 39., 2002, Recife. Anais... Recife: Sociedade Brasileira de Zootecnia, [2002]. (CD-ROM).

PELICANO, E.R.L.; SOUZA, P.A.; SOUZA, H.B.A. et al. Effect of different probiotics on broiler carcass and meat quality. Revista Brasileira de Ciência Avícola, v.5, n.3, p.207-214, 2003.

PELICANO, E.R.L.; SOUZA, P.A.; SOUZA, H.B.A. et al. Productive traits of broiler chickens fed diets containing different growth promoters. Revista Brasileira de Ciência Avícola, v.6, n.3, p.177-182, 2004.

Rostagno, H.S. ALBINO, L.F.T. DONZELE, J.L. et. al. Tabelas brasileiras para aves e suínos: composição de alimentos e exigências nutricionais de aves e suínos. Viçosa, MG: UFV, 2005. $141 \mathrm{p}$.

ROSTAGNO, H.S.; DIONIZIO, M.A.; ALBINO, L.F.T. Perspectivas da nutrição de frangos de corte. In: REUNIÃO ANUAL DA SOCIEDADE BRASILEIRA DE ZOOTECNIA, 41., 2004, Campo Grande. Anais... Campo Grande: Sociedade Brasileira de Zootecnia, 2004. 17p. (CD-ROM).

SANTOS, M.S.; FERREIRA, C.L.L.F.; GOMES, P.C. et al. Influência do fornecimento de probiótico à base de Lactobacillus sp. sobre a microbiota intestinal de leitões. Ciências Agrotecnológicas, v.27, n.6, p.1395-1400, 2003.

STROMPFOVA, V.; MARCINAKOVA, M.; GANCARCIKOVA, S. New probiotic strain Lactobacillus fermentum AD1 and its effect in Japanese quail. Czech, v.50, n.9, p.415-420, 2005. Disponível em: <http://www.vri.cz/docs/vetmed/50-9-415.pdf $>$. Acesso em $12 / 2 / 2008$.

UNIVERSIDADE FEDERAL DE VIÇOSA. Manual de utilização do programa SAEG - Sistema para Análise Estatísticas e Genéticas. Viçosa, MG: Universidade Federal de Viçosa, 1999. 59p.

VARGAS JR., J.G.; TOLEDO, R.S.; ALBINO, L.F. et al. Características de carcaça de frango de corte, submetidos a rações contendo probióticos, prebióticos e antibióticos. In: REUNIÃO ANUAL DA SOCIEDADE BRASILEIRA DE ZOOTECNIA, 39. 2002, Recife. Anais... Recife: Sociedade Brasileira de Zootecnia, [2002]. (CD-ROM). 